\title{
PINTURAS MEXICANAS EN MURCIA Y UN TRÍPTICO MURCIANO DE NUESTRA SEÑORA DE GUADALUPE
}

$\mathrm{POR}$

\section{JOSÉ CRISANTO LÓPEZ JIMENEZ}

$\mathrm{L}$

EVANTE español, de claros celajes, donde florece el almendro y es plaga la chumbera, cabe la sierra de Carrasco y serpentea el río Segura y sumergida en un valle de naranjos, palmeras y limoneros, vive en sus afanes, étnicamente diluida a través de las centurias, una población que en su germen racial como en la estructura de sus calles y viviendas predomina lo semítico. Murcia, pacíficamente entregada al rey clon Alfonso el Sabio, fue cuna de eminentes médicos y filósofos del Islam y en todo tiempo ha dado numerosos artistas; estando tocado el murciano, como gracia, de un innato sentido estético. Renovadas sus construcciones, es una población del dieciocho con blasonados palacios e iglesias de retablos ampulosos cargados de oro, y una torre catedral de casi cien metros de altura semejante a una custodia. Conventos y graciosos campanarios; estrellas y campanas, en las noches claras embalsamadas de azahar y a veces las moriscas melodías de los "auroros". Cuenta Murcia con la primera escuela de imaginería del xvir merced al genial escultor Francisco Salzillo; y su arte, como de litoral mediterráneo, directamente recibió luz de Italia, aun a través de artistas franceses y tudescos. Su arte hermana admirablemente con el de los virreinatos del Nuevo Mundo, no obstante ser Murcia una de las regiones españolas 
de menos emigración hacia América. Sus salidas por mar, más bien se orientaron hacia Italia, sur de Francia y norte de Africa. ${ }^{1}$

Estudioso de las Bellas Artes, al penetrar por mi profesión de médico en los herméticos conventos de clausura, más de una vez he sido sorprendido por obras de interés que no habían sido catalogadas. De la floreciente pintura mexicana del siglo xvin algo se conserva en la ciudad de Murcia. El capuchino cenobio del Santísimo Sacramento es un museo escondido; en la enfermería, un cuadro tenebroso, de un metro de alto por unos setenta de ancho, al óleo en lienzo, de un Cristo de faldetas bordadas y cuatro faroles y florones, lleva al pie las siguientes letras: "Copia del Sagrado bulto de la iglesia del Cardonal, renovado en 19 de mayo de 1621, venerado en el convento de Religiosas Carmelitas Descalzas de S. Josef de México. Adevoción de D. José Tapia, vecino de México. ANDREUS LOPEZ, fecit. Anno 1785. Se tocó al original el 20 de junio de 1785."

Ninguna de las representaciones pictóricas, por mí conocidas en España, de la mexicana Virgen de Guadalupe, posee las excelencias y magisterio de la venerada en la iglesia parroquial de San Juan Bautista, de Murcia. Realizada en un lienzo de un metro y medio de alto por uno de ancho. Obra riquísima en contrastes de colores Iuminosos y corporeidad en las masas, diversificada en tres cuerpos. Azul nocturno, salpicado de soles, es el manto que envuelve desde la cabeza a la Señora, y con destellos de rosa la túnica. Angeles extraños, luces de trópico y rayos y franjas de oro. Recortadas en los cuatro ángulos, sostenidas por infantes alados, cuatro escenas del prodigio mariano. En cinta, pintada bajo la media luna, a los pies de la Madre de Dios, la inscripción siguiente: Michl Cabrera pinxit. Se tocó a su Sagrado original, en el dia 8 de marzo de 1768. En el libro de inventarios de alhajas y vestuarios de 1760 a 1832, consta que don Francisco de Algarra envió a dicha parroquia desde México: "Un crucifijo de marfil con cruz de ébano y remates de plata; un espejo, que está bajo el Santo Cristo, con marco dorado; una imagen de Nra. Sra. de Guadalupe con su retablo dorado;

1 En los archivos murcianos hay escasos documentos relativos al Nuevo Mundo. Después de escarcear profusamente, sólo he encontrado dos escrituras en el de Protocolos; la primera, de 1584, en demanda a Cuzco de los biencs que quedaron por nuerte del jurado Juan Pérez en las minas de Guen Gabalica, dando los hermanos del muerto poderes al padre Jusepe Tiruel, de la Compañia del Nombre de Jesús, y otra en favor de Lorenzo de Gironda, estante en la ciudad de Nuestra Señora de la Paz, del Perú, del año 1608, de pago de 14,450 pesos de plata, en botijas de vino del valle de Siquas. 
una custodia de plata sobredorada, con todo el apostolado y el pie, y San Francisco que sobre su cabeza mantiene la custodia que tiene de peso 200 onzas poco más o menos que la envió de Indias el dho don Francisco de Algarra; una lámpara grande de plata que sirve para el altar mayor tendrá de peso 280 onzas poco más o menos también la envió el referido don Francisco de Algarra y así como la lámpara la custodia y demás alhajas que envió están con la condición de que no se puedan prestar..." (Inventario de 1787). En el inventario de 1832, dice: "Item, un cuadro de Ntra. Sra. de Guadalupe que lo envió don Francisco de Algarra y está en su altar." 2

Estaba creído de que en España sólo había, de Miguel Cabrera, un lienzo de la Santísima Trinidad, en la colección de don Juan B. Meléndez, y el referido de la Virgen de Guadalupe, cuando en visita a la población de Yecla, de la provincia de Murcia, invitado por el profesor don Gratiniano Nieto (hoy director general de Bellas Artes), en la casa de su señor padre político el catedrático jubilado de arqueología don Cayetano de Mergelina (ex-rector de la Universidad de Valladolid), quedé sorprendido ante cuatro grandes lienzos (aproximadamente 1.60 $\mathrm{m}$. de alto por $1 \mathrm{~m}$. de ancho), con escenas de la vida de la Virgen y firmados por Miguel Cabrera, México; haciéndome saber el ilustre dueño que son parte de una colección de quince cuadros, en igual tamaño, de Los Misterios del Rosario; todos pintados -según firma- por Miguel Cabrera y traídos de México a España por un antepasado. Hoy, en virtud de divisiones testamentales, están repartidos entre varios miembros de esta noble familia.

En la casa del autor del presente trabajo, perdura un lienzo de $65 \mathrm{x}$ 50 centimetros, de La Sagrada Familia coronada por la Santisima Trinidad. Pintura amplia y llena, en la que pese a sus hinchados azules y rojizos, domina una tonalidad plomiza. En el plano más bajo de la pintura, recortados arbustos amenizan el término terrenal. Unas letras en el ángulo inferior-izquierdo acusan: Nicolas Martinez picxit Mexici a 1781 .

En los primeros días del mes de enero de 1962, en el estudio de restauraciones que en Murcia posee don Pio Verdú Aparicio, profesor que fue de procedimientos pictóricos de la Escuela Central de Bellas Artes de San Fernando y ayudante de los profesores Núñez de Losada y Stolz

2 Últimamente ha sido colocado el cuadro de Nuestra Señora de Guadalupe, de Miguel Cabreta, en la capilla del bautismo de la Iglesia de San Juan Bautista, de Murcia. 
Viciano, contemplando un cuadro de La Virgen de Guadalupe orlada de flores en fondo blanco, de $1.20 \mathrm{~m}$. alto $\mathrm{x} 0.70$ ancho, desconchado $\mathrm{y}$ falto de limpieza, a la izquierda del ángel y entre las ráfagas y las flores, descubrí, muy vulnerada, la firma "Arellano f.", semejante a otras del pintor Antonio de Arellano. Es propiedad de la familia Pasqual del Riquelme-Herrero Fayrén, de Murcia; traído de México por un antepasado marino.

Desconocedores de la pintura murciana; cuyos maestros - del último tercio del siglo xvi al final del xvi - fueron Artus Tizón o Bran, Cornelio de Amberes, Juan de Alvarado, ${ }^{3}$ Pedro de Orrente, ${ }^{4}$ Lorenzo Suárez y Cristóbal de Azebedo, "Francisco García, Miguel y Juan de Toledo, Nicolás de Villacis, ${ }^{\circ}$ los Gilarte, Senén Vila, etcétera; dijeron, en contra de lo afirmado por don Elías Tormo, que en Murcia no hubo escuela de pintura. Hay desplazamiento continuado de pintores murcianos al centro de la península y Valencia, como fijación en Murcia de artistas valencianos.

Senén Vila, pintor de Valencia, arribado a Murcia alrededor de 1678 , relacionado con el pintor del mismo origen Juan Cunchillos y con el último escultor barroco varonil levantino, Nicolás de Bussi, natural de

3 El arquitecto don Juan B. Belmonte, estudioso de Villacis, en el tercer cuarto del siglo xix, acogiéndose a lo manifestado por Palomino, creyó que el pintor que inició a don Nicolás de Villacis, en su arte, fue Lorenzo Suárez; pero el pintor más relacionado con esta familia Juan de Alvarado, cuyo arte fue muy estimado y querla constancia de haber realizado muchos retablos.

4 De Pedro de Orrente se dudaba su naturaleza, suponiéndole natural de Montealegre, Valencia o Murcia. Recientemente en la iglesia de Santa Catalina, de Murcia, he encontrado su partida bautismal; nacido en Murcia, hijo del comerciante marsellés Jaime de Orrente y de Isabel Jumilla (18 de abril de 1580).

5 De Suárez y Azebedo, recientemente María Luisa Caturla, la investigadora de Zurbarán, me pedía noticias inéditas. Encontré ser Lorenzo Suárez hijo de un bordador murciano del mismo nombre, y el encargo de varias obras; ninguna noticia de Azebedo. En Archivo de Arte Valenciano de 1959 y 1961 sc presentó un cuadro firmado por Suárez y otro por Azebedo hallado en Murcia.

6 También en la iglesia de Santa Catalina de Murcia, he averiguado la particla bautismal de Nicolás de Villacis, discipulo de Velázquez $(9$ de septiembre de 1616). Es tradición que su hermano don Ignacio de Villacis marchó a Nueva España; pero llevó sacados a luz más de ciento cincuenta documentos de esta familia y puedo afirmar no ser cierto. Aparte de los raros Villacis de esta familia, sólo he visto cste apellido en Don Antonio María Bucareli y Ursúa Villasis, caballero de San Juan, virrey sepultado en la colegiata de Nuestra Señora de Guadalupe "Cartilla Vieja de la Ciudad de Puebla", Pedro L. de Villaseñor. Editado por el Instituto de Investigaciones Estéticas, Universidad Nacional Autónoma, México, p. 343). 

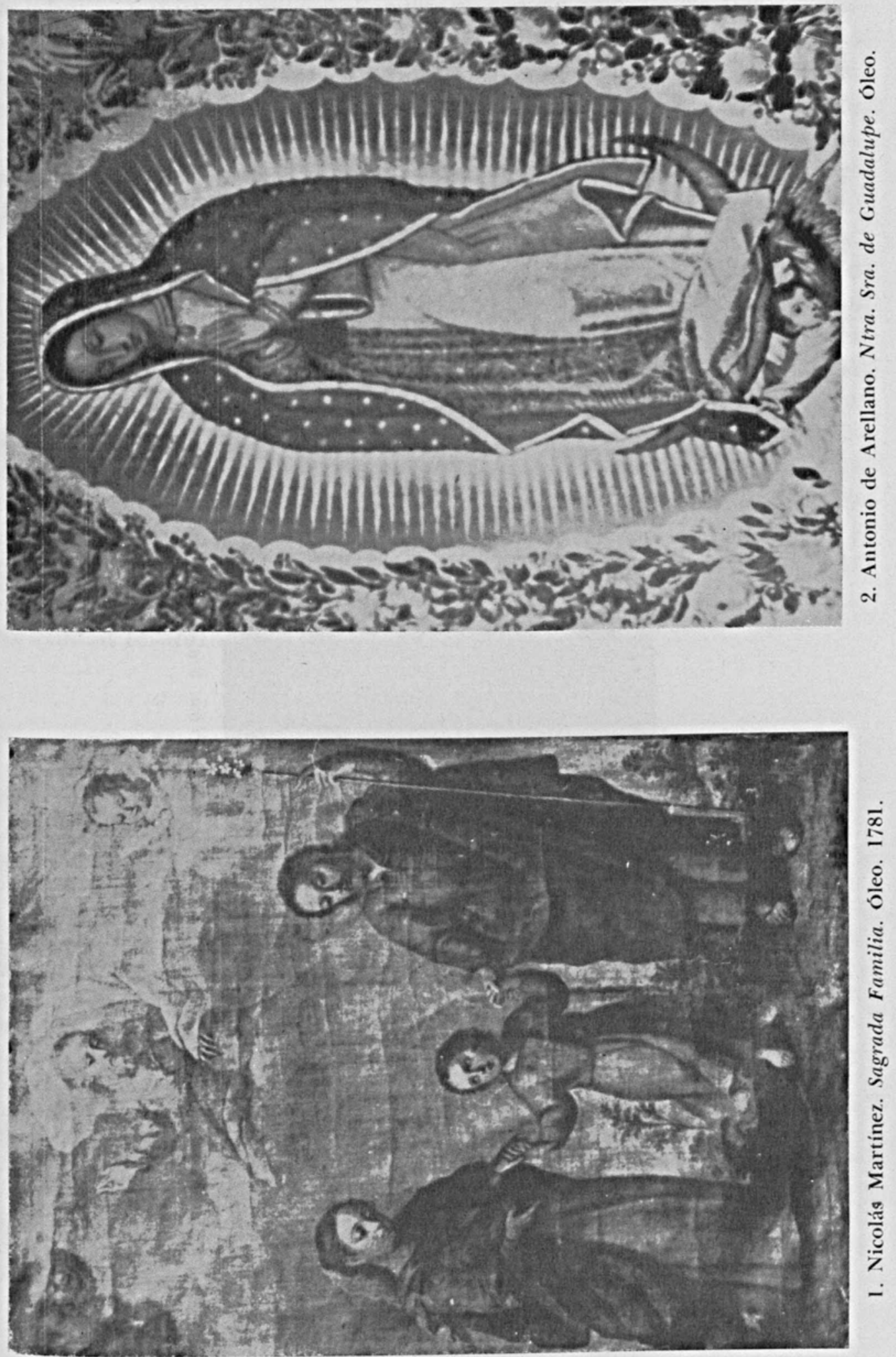
DOI: http://dx.doi.org/10.22201/iie.18703062e.1963.32.757

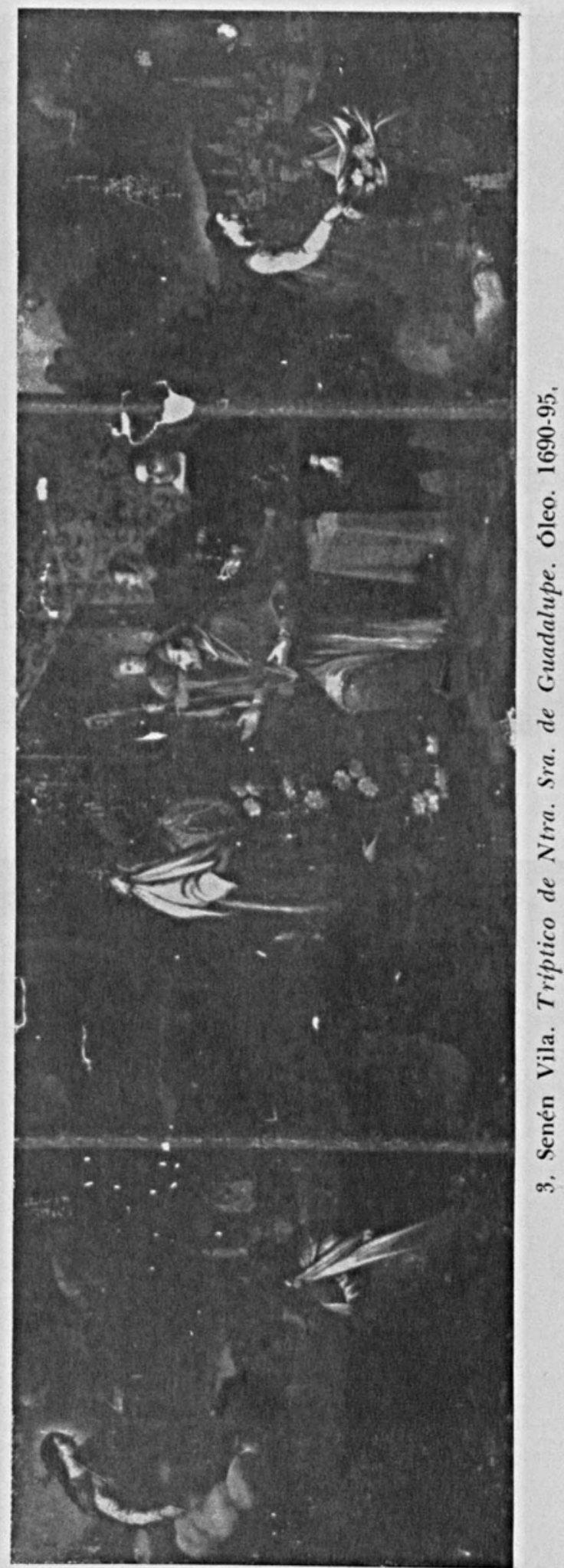


Estrasburgo y misteriosamente llegado en su adolescencia de Italia a Valencia, $\boldsymbol{T}$ formando a veces con ellos academia en Alicante y Murcia, dejó casi toda su obra en esta ciudad, donde murió en 1707, quedando familia, entre ella su hijo Leonardo Vila, sacerdote y pintor. La abundante producción de Senén, desde Valencia a Onteniente, Alicante, Elche y Murcia, patentiza un arte seco y duro, rápido y de admirable dibujo. Senén es el último de la estela de Ribalta.

En tenebrismo hay una interpretación del relámpago, por Senén Vila, en tríptico, hasta hace pocos años poseido por las monjas agustinas de Murcia, que lo recibieron entre 1690 y 1695 , lo vendieron al comerciante señor Hernández Mora; trata de las historias de la aparición de la Virgen de Guadalupe en el Tepeyac al pastor Juan Diego; la impresión de la efigie de la Señora en la tilma de las flores en presencia del obispo Zumárraga y la Virgen llenando flores la tilma del vidente. Es de tradición conventual que el modelo servido por Senén para confeccionar al obispo Zumárraga, en este cuadro, y para la figura de San Lorenzo Justiniano, en lienzo para el convento justiniano de Madre de Dios, de Murcia, fue el escultor Nicolás de Bussi. La ciudad amurallada, del fondo de las hojas del trípitco, fantaseada, tiene las características de una ciudad levantina española.

A cada paso se descubren en España pinturas y esculturas americanas, preferentemente mexicanas, que los funcionarios civiles y militares y los "indianos" solían traer a su regreso. Marfiles llegaban procedentes del archipiélago filipino y las costas asiáticas, pasando a México por el

T "Nicolás de Bussi y la fecha de su muerte", por J. Crisanto López Jiménez, Linea de Murcia, 19 de febrero, 1956. Hace pocos años en el archivo de la iglesia de Santa Maria, de Alicante, descubrí ser Estrasburgo la patria de Nicolás de Bussi ("Archivo Español de Arte", Núm. 13, p. 72), enigmático artista crrante, relacionado con don Juan José de Austria y escultor de cámara del rey Carlos II. Legó a varios lugares de Levante portentosos crucifijos; a Elche, la portada de Santa Maríá a Orihuela, el paso contemplativo de la "diablesa", y a Murcia, entre otras fuertes esculturas, el grandioso Cristo de la Preciosa Sangre. En 1704 marchó a la cartuja de Vall de Cristo, en Segorbe, y trasladado a Valencia, en diciembre de 1706 murió novicio mercedario. El escultor Manuel Tolsá, hijo de la valenciana villa de Enguera, admiraba a Nicolás de Bussi y recibió su influjo a través del Cristo que éste realizó en 1675, en su taller de Alicante, para la parroquia enguerina; y Francisco Salzillo, primero de los escultores españoles del siglo xvin, se formó ante la obra a Murcia dada por Nicolás de Bussi. 
"navio de Acapulco". Se explica por qué tantos los creen marfiles mexicanos, aunque en Puebla de los Angeles se llegó a trabajar bien el marfil. En el convento de Religiosas Descalzas Reales de la Encarnación, de la villa de Mula, en el reino de Murcia, hay un Crucifijo de marfil de gran tamaño, que les fue legado en México en el siglo xvir. ${ }^{8}$

8 Crónica del Monasterio de la Encarnación, fundado en la villa de Mula, por el P. Fr. Ángel de Molina y Castro, de la Regular Observancia de San Francisco. Murcia, 1779 . 